\title{
Research on the Space transformation of Yungang Grottoes Art Heritage and the Design of wisdom Museum from the perspective of digital Humanity
}

\author{
LiuXiaoDan $^{1,2}$, XiaHuiWen $^{3}$ \\ ${ }^{1}$ Jinzhong college, Academy of fine arts, Jinzhong ShanXi, 030619 \\ ${ }^{2}$ Nanjing University, School of History, Nanjing JiangSu, 210023 \\ ${ }^{3}$ Taiyuan University of Technology Academy of arts, Jinzhong ShanXi 030606 \\ *Corresponding author: LiuXiaoDan, No. 199 Wenhua Street, Yuci District, Jinzhong City, Shanxi Province, 030619, China.
}

\begin{abstract}
The pace transformation and innovative design of Yungang art heritage should keep pace with times on the setting of "digital humanity" times, make the most of new research approaches which is given by "digital humanity" and explore a new way of pace transformation of art heritage actively. The research object of this topic is lineage master in space and form and the transformation of promotion and Creativity of Yungang Grotto art heritage. The goal is taking advantage of big data basics and the information sample collection and integration in the context of the full media era. Transferring Yungang Grotto art materially and creatively by making use of the world's advanced "art + science and technology" means, building a new type of modern sapiential museum and explore the construction mode of it and the upgraded version of modern educational functions.
\end{abstract}

\section{Introduction}

Yungang Grotto represent the highest level of north royal grotto art in the 5th century AD. Compared with many grottos in China, it has the most western style. Yungang Grotto not only has elements of Indian, Central and Western art but also has Greek and Roman architectural modeling, decorative patterns, appearance characteristics and so on. It embodies the variety of Buddhist art image style of fusion and it is the crystal of exchanges among different civilizations are converging. As the world's outstanding cultural heritage, it is obvious that Yungang Grottoes is suffering from serious damage of the nature. So, cultural relic digitization and artistic heritage space transformation are materially and spiritually the top priorities. When president Xi Jinping visited the Yungang Grottoes in Datong in 2020 to investigate the protection of the historical and cultural heritage, he said: "The Yungang Grottoes reflect the feature of Chinese culture and the history of cultural exchanges at home and abroad and they are a treasure of human civilization. We should persist in protecting them first and making good use of them on the basis of protection. In particular, we should improve the level of protection and utilization with advanced science and technology and pass on this cultural heritage of the world from generation to generation. On the setting of "digital humanity" times, The pace transformation and innovative design of Yungang art heritage should keep pace with times, make the most of new research approaches which is given by "digital humanity" and explore a new way of pace transformation of art heritage actively. During the long race against the "disappearance" of cultural relics, the design of the wise exhibition platform of Yungang Grottoes is not only a storage and display for existing cultural relics, but also a new culture and art complex in contemporary era. Therefore, the Yungang Grottoes Wise Museum designed and constructed by this theme is committed to inheriting the excellent traditional Chinese culture and art, that is, to use the inheritance, promotion and creative transformation of the excellent material cultural heritage of Yungang Grottoes in space and form, so as to realize the creation of the wise exhibition platform for the spatial transformation of Yungang Grottoes art heritage.

\section{Approach And Methodology Of Space Transformation Jof Yungang Grotto Art Heritage}

In this section, we transfer recovery technology, roundly refer and actively explore the world's advanced experience with the transformation of promotion and Creativity of Yungang Grotto art heritage. We deepen and expand on the basis of preliminary research and he innovation and put them to innovate and promote art teaching materials of discipline construction and art teaching AIDS, and then build a new design model of smart museum finally. We mainly through the following three ways:

First, upgrade Yungang research. One the one hand, 
apply artificial intelligence, big data and other digital technologies to the research field of Yungang Science, provide new methods and paradigms to it and breathe new life into it. The construction of this project is also the research achievements of "the Study of Yungang ", as well as an effective way to construct double first-class disciplines in colleges and universities, and a new attempt of the modern laboratory model in art teaching system.On the other hand, introduce the accumulated academic in the research field of Yungang science into the Internet environment and build a richer and more diverse network information ecosystem guided by the humanistic spirit. Specifically: collecting relevant academic information (sculptures, murals, construction) of the Yungang grottoes in the history, sorting out of the academic problem about the Yungang grotto art heritage and "Yungang mode" formation, spread and so on in the Northern Wei dynasty, determine its historical value and determining its outcomes with universal values of historical value, carving skills and cultural connotations. Preparing for the effective show at the museum of new wisdom well, forming the cultural relics and sites and converting innovation to a contemporary new cultural resources and cultural creative industry.

Second, in the context of the full media era, we research some problems like the spatial transformation, activation and utilization of the excellent cultural heritage in Yungang Grottoes. Using the means of "art + technology" to explore the transfer of space matter, replication and creation of Yungang grottoes and find the effective way and method to solve a problem about its inheritance of the excellent material cultural heritage, carry forward and creative transformation. Exploring new "art + technology" model for calligraphy or painting and realizing the upgrading of production approaches of emerging culture and the transformation of production path from cultural undertaking to cultural industry to cultural entrepreneurship. It injects new vitality to the traditional technology and gives the meaning of the new era. For example, constructing the concept design of a new smart museum, and collecting and integrating big data and information samples by means of "art and science and technology"; Exploring the establishment of a new type of scene experience laboratory and appearing the ancient art through information-big data technology and form of transform and innovation in the form of acoustic, photoelectric and touchable display.

Third, learning from the world's advanced experience and transfer recovery technology by mobile access in a network environment which is provided by mobile Internet technology. Deepening and expanding on the basis of preliminary research, putting them into practice in discipline construction, innovating and promoting art teaching AIDS and promoting intelligence of digital museum and its behavior and environment. For example, designing model of the wisdom museum creating the "model room" of it in the form of digital media (VR, AR) online (online museum) or physical reconstruction in different places (material transfer and innovation). This "model room" can present Chinese latest research achievements in the field of "art and science" to the world, realize the integration and innovation of art and science and also transform it into cultural and artistic productivity. Then, the project of Wisdom Museum in Yungang Grottoes should be implemented by means of contacting with school, government and enterprises; and then, promoting this mode comprehensively along with the Belt and Road countries and making it a cultural and travel experience base for the inheritance of excellent traditional Chinese culture and excellent culture and art along the Belt and Road.

\section{Design Model Of Yungang Grottoes Art Heritage Wisdom Museum}

How to build the model of Yungang grottoes art heritage wisdom museum?

The object of the wisdom museum constructed by this topic is Yungang excellent cultural heritage. Taking advantage of new "art and technology" approach, merging university, scientific research platform, education and training base, museum, art gallery, gallery and other functions into a synthesis of integration of production, study, research and application of culture and art. It includes the cultural and technological innovation platform and carrier of protection, restoration, transfer and creation of cultural heritage and other aspects. The design model of its wisdom museum mainly includes the following aspects:

1. Large scale restoration.

Large scale restoration refers to the comprehensive transboundary new form of preservation and restoration and it integrate and innovate the essence of eastern and western restoration technologies. The traditional Chinese art, such as colored drawing, fresco, sculpture, and utensil (mental, ceramics and lacquerware) and international advanced repair technology-- multidimensional spectrum analysis technique and overall repair transfer are merged into repair system which is mainly an experiential museum. With the conception of "great restoration", based on preservation and restoration, this research applies advanced experience and transfer and restoration technologies at home and abroad, utilize the means of "art + science and technology" to collect and integrate big data and information samples, in order to get a longer and better revive of Yungang Grottoes, which not only relies on means of digital collection and display but also requires more interpretation of basic knowledge. Only by combining knowledge as an extended dimension with yungang's visual images, can it show yungang's deep value. In addition, the construction of such knowledge latitude fully shows the ability of knowledge map connection and retrieval ability in the current field of artificial intelligence and reaches a level that is beyond the memory and understanding of human beings.

2. Art and technology.

This project is committed to the inheritance, promotion and creative transformation of the excellent cultural heritage of Yungang Grottoes. The main purpose of the research is to integrate the big data basis and information sample collection, and to transfer and create the classical works of art of Yungang Grottoes in the way of "technical art". Base on the technology for the 
protection and restoration of cultural relics commonly used internationally and lead by "Art History of Technology", constructing the industrial form of cultural and technological innovation, merging traditional intangible cultural heritage and modern high technology and providing theoretical support for building "foundation for the inheritance of Chinese excellent traditional culture" jointly.

\section{Intangible cultural heritage technology}

Rising the research of the inheritance of intangible cultural heritage to the level of discipline construction. With the concept of "Intangible cultural heritage", integrating factors such as inheritor, large scale restoration, intangible cultural, historical background, artistic work and so on and creating a form of intangible cultural heritage that meets the requirements of the new era. The main method is presenting the historical and cultural value of intangible cultural heritage by spatial form of comprehensive situational full sensory experience. It's also the type of innovation of "a new type of museum or laboratory".

4. Experience of space design.

Researching human experience needs of space and time in the new century technically. On the base of the combination of the epistemology of the idea of large scale restoration and the methodology of total sensory experience, adding a micro display of the deep section and creating an enhanced experiential museum space with a highly integrated scene representation and real experience

5. Establish a new situational experiential classroom or art teaching materials model.

As the carrier of the construction of the subject of "technical art", museum, internal equipment and instruments which include the process of repairing and creating of wisdom experiential museum could become the content of on-site teaching of experiential wisdom museum. We could see that how to combined the most leading-edge technology with ancient art and it is typical and new examples of art teaching AIDS of "science and art". More specifically, the new situational experiential classroom/art teaching materials and teaching AIDS model is able to realize the display form with sound, light and touch in the situational experience room. This kind of experience classroom or laboratory is not only the platform and carrier of art education under the background of cultural and technological innovation, but also the practice of "technical art".

6. It will become a base for the inheritance of Chinese excellent traditional culture.

The establishment of a new type of experiential classroom of attaching importance to the research on new restoration, transfer and innovation of cultural and that gave birth to international joint laboratory, technology transfer Center (restoration technology, virtual technology, art craftsman of major power), the construction of the wisdom museum and so on) are seamless connection and applying their knowledge. The social implementation of advanced ideas of international cultural travel study builds a base for the inheritance of excellent traditional Chinese culture and serves college teaching and local tourism industry. In brief, based on the subject "technical art", the research is dedicated to combine art, aesthetics, history, the Chinese learning and so on various disciplines as a contemporary new practice, and tries to transform the international frontier subject--protection and restoration of cultural heritage into a wholly new Oriental vision , with the hope of realizing the combination of Renaissance "art" and "science" and "technology", and also providing support and solutions of conversing cultural relics and ancient arts into innovative cultural resources and cultural creative industry.

\section{Realizing The Significance And Value Of Yungang Grottoes Wisdom Museum}

The plan of Yungang wisdom museum system is not a single house for the storage of fragments, but a cultural and artistic complex that gathers the function of institutions of higher learning, research platforms, education and training bases, museums, art galleries and galleries; and it also can provide a new model of "art + technology" for calligraphy or painting. It is also the combination of discipline construction and scientific and technological innovation and an effective way to realize the integration of production, study, research and application; It is the platform and carrier of art education under the background of cultural and technological innovation and also the inheritance base of excellent traditional Chinese culture and excellent culture and art along the Belt and Road. In summary, through building up a wise display platform, the research aims at providing more opportunities to protect, revive, and promote the development of the cultural heritage of Yungang Grottoes, and also providing diversified solutions for the inheritance, creation and revival of ancient art classics.

Yungang Grotto wisdom museum has a great role in promoting and driving for culture and tourism. Facing the digital age, historical and cultural tourism of Shanxi must also keep pace with the Times and fully develop digital historical and cultural tourism. The systematic design plan of Yungang wisdom museum is a new plan of contemporary excellent cultural heritage of the "digital humanities" products. The purpose is letting visitors to get what they want by various digital modes. And it not only improves the level of tourism service, but also improves the quality of tourism service. This plan can promote development of Shanxi cultural industry better and more prosperous.

(Postscript : the idea of this paper is from the learning of the project named "Art restoration and training of talents", which author practiced in 2008, sponsored by national Renmin University of China, and benefit from the teaching and assistance of professor Ding Fang who is working at the School of Art, Renmin University)

\section{Found Program:}

1.Philosophy and Social Science Project of Colleges and Universities in Shanxi Province in 2020: The research on animal Images in Chinese Buddhist art (2020W184)

2. 2019 Jinzhong "1331 Project" Innovation Team project: Research on cultural Heritage Inheritance and Cultural tourism Strategy in Shanxi (jzxycxtd2019002)-- 
Stage results

\section{About The Author:}

1. Liu Xiaodan (1983-), male, yuanqu, Shanxi, PhD candidate, Department of Archaeological relics, School of History, Nanjing University, associate professor, Vice President, Shanxi Jinzhong Academy of Fine Arts, Tutor for postgraduate of Art School, Taiyuan University of Technology, Researcher of Jinzhong Cultural Ecology Research Center. Research interests: Art archaeology, cultural heritage and culturology reseaching. 2.Xia Huiwen (1996-), female, Datong, Shanxi, Master candidate, School of Art, Taiyuan University of Technology.

\section{References}

1. Zhao Yvxiang, Lian Jingwen, A Review of research on summarize of cultural Heritage from the perspective of digital humanities. [J]. data analysis and knowledge discovery, 202010.14

2. Du Juan, Liu Huihui,"Digital" opens a new horizon of "humanities". [J]. Social Science Journal, 2020.8.27

3. Sheng Jielin, The Enlightenment of "Digital Dunhuang" project to the protection of Chinese cultural heritage. [J]. weekly of Chinses cultural relics.2020.06.23

4. Liu Xiaodan, An Analysis in the Origin and Development from Yungang Grottoes Art in the Northern Wei Dynasty[J]. Journal of Jinzhong University. September 27, 2020.

5. Chen Changxing and Chu Deping, improvement on the "smart service" level of museums [N]. China Social Science News, August 19, 2020.

6. Li Huabiao, the smart museum and the construction of the big data model[J]. Electronic technology. June 20, 2020.

7. Zhang Likun and Zhang Lihong, Preliminary Exploration in Museum Data Visualization Platform- Taking Nanjing Museum exhibited Special as an Example[J]. The Southeast Culture. August 30, 2020

8. Diao Changyu, Li Zhirong. High-fidelity digital technology and application from stone cultural relics[J]. Chinese Cultural Heritage, 2018(04): 61-67.

9. He Yunao. Archaeology is the foundational stone of the development of modern museums [J]. Popular Archaeology, 2017(02): 4.

10. He Yunao. the premise of material cultural innovation is the innovation of ideas is proved by the Archaeology[J]. Popular Archaeology, 2015(09):1.

11. He Yunao. In the construction of modern Chinese civilization that the excellent traditional culture plays a fundamental role [J]. Popular Archaeology, 2014(03):1. 